\title{
A Brief Analysis of Taiwan's Nation
}

\author{
Haoran $\mathrm{Nie}^{1, \mathrm{a}}$ and Wandi $\mathrm{Pei}^{2, \mathrm{~b}}$ \\ ${ }^{1}$ School of literature, Jinan University, Guangdong, China \\ ${ }^{2}$ School of literature, Guangdong Polytechnic Normal University, Guangdong, China \\ anie_hao_ran@126.com, ${ }^{b} 1525137293 @ q q . c o m$
}

Keywords: Taiwan Island, aborigines, the Hakka,the Heluo.

\begin{abstract}
Taiwan's 'Yuanzhu' people mean the original inhabitants of Taiwan Island. They stem from aborigines, the Heluo and the Hakka. These people compose Taiwan Island's original inhabitants. These nations have distinguishing features. Studying on Taiwan Island's original inhabitants can help us know Taiwan Island nowadays and foster China’s self-identity.
\end{abstract}

\section{Introduction.}

Taiwan's people consist of aborigines( the Gaoshan nation), the Heluo (usually called Fulao) and the Hakka. They are usually called “our country's people”. Actually these three nations come from mainland China directly or indirectly. The time they come to Taiwan Island are different, sooner or later.

Taiwan nation's research findings nowadays, include Huang Haichun's master degree essay, the historical process of Taiwan Aborigines' identity. ${ }^{(1)}$ This essay writes Taiwan aborigines' classification according to 3 periods, Qing Dynasty, the time Taiwan Occupied by Japan, and the time Taiwan controlled by National Government. Li Yiyuan's essay, Taiwan aborigines' society and culture, concludes Taiwan's aborigines from nation science, anthropology, sociology and politics. There are also other correlation studies such as Wei Huilin and Liu Binxiong's essay, Lanyu Islet Taimei Nation's social organization, Huang Yinggui's Taiwan aboriginal society and culture study essay, and so on.

\section{The aborigines}

The aborigines of Taiwan Island ( the Gaoshan nation), usually called 'Dong Foreigners' during Ming Dynasty, 'aborigines' during Qing Dynasty, and also called 'foreigners'. They are called "Tufan, Yefan and Shengfan" according to their different Chinesization. They can also be called "Hua fan, Shu fan or Pingpu fan”, different from the Gaoshan Nation. When Taiwan were taken over by Japan, they are called "Gaosha Nation". These forms of calls are convenient, they have no scientific meanings, so they are called the Taiwan Aborigines suitable.

The aboriginal nations, half of them distribute in central mountains of Taiwan Island, the other of them distribute in plain, seacoast, and islands. These people are 200 thousand. 50 thousand are called "Shu Fan" or "Pingpu Fan", they are almost Chinesized, so they live consist with Heluo and Hakka. Only few of them keep in their settlement. But they have already lose original form lifestyle in culture. Only 100 thousand people who live in mountains and 50 thousand people who live in near east seacoast area and islands keep their normal lifestyle and settlement.

Mr. Chendi writes in his $<$ Dong Fan Ji $>$ about the aborigines that "Dong Fan aborigines, they are not known where they come from, live in islands outside the Penghu. They live in WangGang, Jialao Gulf, across DaYuan, YaoGang, Dagou Yu, Little Danshui, Double Streams, Jiali Forest,

\footnotetext{
(1) Huang Haichun: < the historical process of Taiwan Aborigines' identity.>, Minzu University of China, master degree essay.
} 
Shaba li, Dabang keng. All are their settlement. To continue going about thousand miles, there is their settlement. One thousand or five hundred people are a settlement. They have no leaders. The person who have more offsprings are their boss. They are brave, they like fighting. They can run days and nights. Their feet are inch thick. They run in thickets like running on the plain. They are as fast as horses. They do not need relaxing. In brief, they can go hundred miles. If they have contradiction with neighbor, they would fight to them with swords, and they can become reconciled soon. The person beheaded would be peeled his meat and left bones, his head hanged on the door. They are called 'Zhuang Shi ' when their bones are more. As the floor are worm, people dress no clothes no matter winter or summer. Female are with hula skirt, only covering their private parts. They have no fell down ceremony, no calendar. Full moon is a month, 10 month is a year. As time passes, they forget their age. The people do business by ropes. They have no paddy field. When follows blows, they plough. When seedlings of cereal crops ripe, spikes were plucked. The rice there is longer than Chinese rice, and it smells sweet. Getting eel grass to make rice wine, man can drink a dou. When dinner comes, all people get together around a big pan, drinking by bamboo tubes, with no cooked dishes. They dance and sing. Man cut their hair with only a little left. Woman do not. Man pierce their ear lobes, woman cut their teeth. There are so many bamboos on their settlement, wide and long. Aboriginal people cut bamboos to build houses. The nation live in a room, one which is a little bigger can live the young unmarried man. Meeting must be held in a public area." (2)

The above are the initial records of Taiwan aboriginal people. It detailed describes Gaoshan Nations' animation and their contact with Han nation. According to academic research, Taiwan aboriginal nations consist of 9 nations, Taiya, Saixa, Bunong, Cao, Lukai, Paiwan, Beinan, Amei, Yamei. When Taiwan come back to China from Japan, experts find that Gaoshan people coming from mainland China. Wei Huilin holds that we should refuse that Gaoshan people are the Malayan people. And we also cannot overall emphasize they all come from mainland China. They belong to old and new, north and south, two systems. The nation living in north and central mountain areas of Taiwan Island belong to old mainland cultural system, the east and the plain belong to south island cultural (Indonesia cultural ) system. So we can say mainland China nation is the bassinet of Southeast Asia culture and the Pacific Ocean culture. And the south nations also have contact with mainland China.

We can also study the origin of nations according to legends. Nowadays we can also find ancestors' birthplace according to Taiwan aboriginal legend. Even if the birthplace of their ancestors cannot demonstrate their origin of their nations, it can at least show the initial settlement of their ancestors. The legend of this can divide into three classes. First, they come from mountains. The nation living in mountains nowadays belong to this. They most know the meaning of ocean, and pay their attention to mountain. For example, Taiya's Sedek take Beigang Stream's upstream Pinsebnkun as their birthplace. Tseole take Dabashan Mountain's Papakwa-aw as their birthplace. Syxia take Oppeht Naboon as their birthplace. Caozu take Patungkanu as their birthplace. Lukai take central mountains Kaliala Mountain as their birthplace. Paiwan take Kavoroyay as their birthplace. Dubunong take western plain coast Lamongan area as their birthplace. Second, they come from plain and seacoast. Amei Nation's Tsiwalian take Shuilianwei as their birthplace. Patssilar take Teng aran as their birthplace. These areas all belong to seacoast areas. Third, they come from high seas. Most of Amei, Pingpu and Yamei belong to this kind. Most Amei take Sanasai as their ancestors, so their birthplace is in the oversea area. Yamei's Ivarlinn and Ivatan know their ancestors come from Ivatan. From these three legends, we know that the Gaoshan Nation must come to Taiwan very early. They may have no contact with south island system. They may come directly from mainland. However, the plain and highsea people are actually later coming. They come from Indonesia or Philippines. This presumption is the same as prehistorical culture.

\footnotetext{
(2) Shen Yourong:< Min Hai Zeng Yan>, <modern Chinese historical datum collection and edition>,sequel, the 51th edit, Taipei: Wen Hai publishing company, 1978, page34-36.

(3) Taiwan literature committee: <Taiwan General history>, Taipei: Zhongwen books company, 1980, vol. II, page 10.
} 


\section{Heluo and Hakka}

The 'Bensheng people' is a political word. It means the offsprings of immigrants from mainland China to Taiwan Island, from Ming and Qing Dynasty to nowadays. It also means the offsprings of Heluo and Hakka. It includes few other provinces' immigrates. The Qing Government called them Han people, and also call them 'Liuyu'.

From Ming Dynasty, seacoast inhabitants most immigrate to Taiwan due to fishing, pirates or food. Especially Fujian Province and Guangdong Province, as there are more mountains and little fields, so the people are accustomed to sea, more people go over sea to Taiwan Island. When Qing Dynasty replaces Ming Dynasty, there are more adherents of Ming Dynasty going to Taiwan Island from Mainland China. So the immigrants consist of three types, such as adventures on the sea, adherents of Ming Dynasty, the soldiers fighting with the army, people running away from social upheaval, fish men for business.

When they first arrived, they found Taiwan Island is with much land and few people. This is a block of undeveloped land. The Gaoshan Nation are distributed in everywhere. The Gaoshan Nation are not too good at ploughing, accumulating, business, they are only good at hunting. So Fujian and Guangdong immigrants are engaged in reclaiming wasteland, and eventually they make uninhabited island into happiness land on the sea.

Somebody says, Taiwan Island's mountains are all reclaimed and no land left waste. However, they are not aware at the beginning of their immigrating, a lot of Fujian and Guangdong immigrants bleeding and sacrificing to get Taiwan Island's foundation.

For instance, first, at that time, immigrants use sailing boats arriving and departing Taiwan Island and Mainland China. Sailing boats are easy to shipwreck when they get storm wind. So a lot of people are submerged under the sea.

Second, at that time, Gaoshan Nation are easy to fight. Fujian and Guangdong immigrants are living mixed with Gaoshan Nation. The immigrants were usually killed by Gaoshan Nation due to little contradiction. Their houses were destroyed too many to count.

Third, at that time, Taiwan Island were with miasm, epidemic diseases were usually spread. Fujian and Guangdong immigrants got sick and dead due to no medical treatment more and more.

Fourth, as mainland China and Taiwan Island have different environment, a lot of Guangdong and Fujian immigrants dead as they do not suit Taiwan Island's environment.

Moreover, there are also some other people dying due to natural calamities and man-made misfortunes. We do not need to write more here.

And the paths from mainland to Taiwan Island, Fujian immigrants went from City Xiamen, Guangdong immigrants went from City Haicheng to Tainan, Lugang and Balipen. And then due to Access Control, stowaway usually got to Taiwan Island from DongGang, Dagou(City Gaoxiong nowadays), BenGang in central, ZhongGang in the north, Wushi Gang in the east.

Immigrants from Fujian Province, as they coming to Taiwan Island very early, most spread in the western port areas. Then they move into inland. Immigrants from Guangdong Province, as they move to Taiwan Island later, so they most spread in near mountain areas. Most of the immigrants are from Fujian Province, only few of them are from Guangdong Province.

There is a research in the Republic of China 17 years (1928 AD) writing Taiwan people's ancestor resource.

Taiwan Island people, most of them are from Fujian province, then are from Guangdong province, left are from other provinces. Fujian immigrants are quintupling than Guangdong immigrants, 63 times more than other provinces. Most of Fujian immigrants are from Quanzhou and Zhangzhou, left are from Tingzhou, Fuzhou, Yongchun, Longyan, Xinghua. Most Guangdong immigrants are from Jiaying Zhou, then left are from Huizhou and Chaozhou. 
There is a table about Taiwan immigrants and their ancestral homes.

\begin{tabular}{|l|l|l|l|l|}
\hline $\begin{array}{c}\text { Ance } \\
\text { stral } \\
\text { home } \\
\text { People }\end{array}$ & Fujian province & $\begin{array}{l}\text { Guangdong } \\
\text { province }\end{array}$ & $\begin{array}{l}\text { Other } \\
\text { provinces }\end{array}$ & Total \\
\hline Taipei People & 710100 & 4300 & 5600 & 726000 \\
\hline $\begin{array}{l}\text { City Xinzhu } \\
\text { People }\end{array}$ & 217100 & 353300 & 11700 & 582100 \\
\hline $\begin{array}{l}\text { Taichung } \\
\text { People }\end{array}$ & 736200 & 107700 & 107700 & 853800 \\
\hline $\begin{array}{l}\text { Tainan State } \\
\text { People }\end{array}$ & 979300 & 20500 & 100600 & 1010400 \\
\hline $\begin{array}{l}\text { Gaoxiong } \\
\text { People }\end{array}$ & 387100 & 92000 & 10600 & - \\
\hline Taidong People & 3700 & 1200 & - & 4900 \\
\hline Hualian People & 9900 & 7200 & - & 17100 \\
\hline Penghu People & 67000 & 100 & 500 & 67600 \\
\hline
\end{tabular}

From: [Japan] Taiwan Palazzo Ducale research center: Taiwan people’s ancestor home research, 1928.

\section{Conclusion}

Taiwan Island people consist of the aborigines, Heluo and Hakka. They are from mainland China sooner or later. Actually they are from mainland China directly or indirectly. Aborigines, Heluo and Hakka have their own different lifestyles. The origin of aborigines are from mainland China or from Malayan. Some other people also say they are from mountains, plain, near seacoast or from abroad. Taiwan aborigines have their own special lifestyle, eating customs, dress, marriage customs and business style. Heluo and Hakka people are the offsprings of Guangdong and Fujian immigrants during Ming and Qing Dynasty. The immigrants from mainland China to Taiwan have 5 styles, such as adventurers on the sea, adherents of Ming Dynasty, soldiers fighting with the army, people running away from social upheaval, and the people for fishing and business. According to Japanese Government research, Fujian people are spread in the western port areas of Taiwan Island, as they immigrate sooner. Guangdong people are spread in eastern Taiwan Island near mountain areas as they immigrate to Taiwan Island later. Studying historical Taiwan nations is meaningful to understand Taiwan nation nowadays. So we can say most Taiwan people come from mainland China in ancient time, Taiwan island is a part of China in history and now. Taiwan peole are Chinese. We can foster China's self-identity.

\section{References}

[1] Taiwan literature committee: Annals of Taiwan Province, vol.2, the people, Zhongwen Books Company.

[2] Huang Haichun: < the historical process of Taiwan Aborigines'identity.>, Minzu University of China, master degree essay.

[3] Zhang Yinhua:<Taiwan :nation and national policy>, forward position,2008(3).

[4] Zhao Jiawang:<The summary of Taiwan nation study>, academic journal of Guangdong Minzu 
University, edition of social science, 1995(3).

[5] Wu Jianguo:<an analysis of Taiwan nation>, academic journal of southwest Minzu University, edition of social science, 2000(2).

[6] Li xin:<economic policy of Taiwan aborigines>, Minzu University of China , master degree essay.

[7] Lang Weiwei:<The development of Taiwan nation>, Minzu academic journal, 2016(2).

[8] Hao Shiyuan:<Taiwan's aborigine and problem of nationality>, Ethnic Studies, 2003(3).

[9] Shen Yourong: < Min Hai Zeng Yan>, < modern Chinese historical datum collection and edition>,sequel, the 51th edit, Taipei: Wen Hai publishing company, 1978.

[10][Japan] Taiwan Palazzo Ducale research center: Taiwan people’s ancestor home research, 1928. 